\title{
In vivo genetic engineering of murine pancreatic beta cells mediated by single-stranded adeno-associated viral vectors of serotypes 6,8 and 9
}

\author{
V. Jimenez • E. Ayuso • C. Mallol • J. Agudo • \\ A. Casellas • M. Obach • S. Muñoz • A. Salavert • \\ F. Bosch
}

Received: 16 September 2010 /Accepted: 2 January 2011 /Published online: 11 February 2011

(C) Springer-Verlag 2011

\begin{abstract}
Aims/hypothesis The genetic engineering of pancreatic beta cells could be a powerful tool for examining the role of key genes in the cause and treatment of diabetes. Here we performed a comparative study of the ability of singlestranded (ss) adeno-associated viral vectors (AAV) of serotypes 6,8 and 9 to transduce the pancreas in vivo. Methods AAV6, AAV8 and AAV9 vectors encoding marker genes were delivered to the pancreas via intraductal or systemic administration. Transduced cells were analysed by immunostaining. AAV9 vectors encoding hepatocyte growth factor (HGF) were delivered intraductally to a transgenic mouse model of type 1 diabetes and glycaemia was monitored. Results AAV6, AAV8 and AAV9 mediated efficient and long-term transduction of beta cells, with AAV6 and AAV8 showing the highest efficiency. However, alpha cells were
\end{abstract}

Electronic supplementary material The online version of this article (doi:10.1007/s00125-011-2070-3) contains supplementary material, which is available to authorised users.

\footnotetext{
V. Jimenez $\cdot$ E. Ayuso $\cdot$ C. Mallol $\cdot$ J. Agudo $\cdot$ A. Casellas $\cdot$

M. Obach $\cdot$ S. Muñoz $\cdot$ A. Salavert $\cdot$ F. Bosch $(\bowtie)$

Center of Animal Biotechnology and Gene Therapy, Edifici H,

Universitat Autònoma de Barcelona,

08193 Bellaterra (Barcelona), Spain

e-mail: fatima.bosch@uab.es

V. Jimenez $\cdot$ E. Ayuso $\cdot$ C. Mallol $\cdot$ J. Agudo $\cdot$ A. Casellas $\cdot$

M. Obach $\cdot$ S. Muñoz $\cdot$ A. Salavert $\cdot$ F. Bosch

Department of Biochemistry and Molecular Biology,

School of Veterinary Medicine,

Universitat Autònoma de Barcelona,

Bellaterra (Barcelona), Spain

V. Jimenez $\cdot$ E. Ayuso $\cdot$ C. Mallol $\cdot$ J. Agudo $\cdot$ A. Casellas $\cdot$

M. Obach $\cdot$ S. Muñoz $\cdot$ F. Bosch

CIBER de Diabetes y Enfermedades Metabólicas Asociadas

(CIBERDEM), Spain

URL: www.ciberdem.org
}

poorly transduced. Acinar cells were transduced by the three serotypes tested and ductal cells only by AAV6. In addition, intraductal delivery resulted in higher AAV-mediated transduction of the pancreas than did systemic administration. As proof of concept, intraductal delivery of AAV9 vectors encoding for the beta cell anti-apoptotic and mitogenic HGF preserved beta cell mass, diminished lymphocytic infiltration of the islets and protected mice from autoimmune diabetes. Conclusions/interpretation Intraductal administration of AAV6, AAV8 and AAV9 is an efficient way to genetically manipulate the pancreas in vivo. This technology may prove useful in the study of islet physiopathology and in assessment of new gene therapy approaches designed to regenerate beta cell mass during diabetes.

Keywords Adeno-associated vectors · Beta cells . Diabetes · Gene therapy · Gene transfer · Pancreas

$\begin{array}{ll}\begin{array}{l}\text { Abbreviations } \\ \text { AAV }\end{array} & \begin{array}{l}\text { Adeno-associated virus } \\ \text { AAV9-mHGF }\end{array} \\ \text { AAV encoding the murine HGF driven } \\ \text { by the CMV promoter } \\ \text { Cytomegalovirus enhancer/chicken } \\ \text { beta-actin constitutive promoter } \\ \text { Cytomegalovirus constitutive promoter } \\ \text { CMV } & \begin{array}{l}\text { Double-stranded } \\ \text { ds }\end{array} \\ \text { GFP } & \text { Green fluorescent protein } \\ \text { HGF } & \text { Hepatocyte growth factor } \\ \text { KO } & \text { Knockout } \\ \text { RIP } & \begin{array}{l}\text { Rat insulin promoter } \\ \text { Ss }\end{array} \\ \text { vingle-stranded } \\ \text { WPRE } & \text { Viral genomes } \\ & \text { Woodchuck hepatitis virus posttranscrip- } \\ \text { tional regulatory element }\end{array}$




\section{Introduction}

Diabetes mellitus is the most common metabolic disease; its characteristic hyperglycaemia is a consequence of defects in insulin secretion and/or insulin action and ultimately results in reduced beta cell mass [1]. Nevertheless, the mechanism (s) involved in the pathogenic process(es) that lead to the loss of beta cells and development of the disease are not fully understood. Moreover, some forms of diabetes have no known aetiologies [1]. In vivo genetic engineering of the pancreas, with special emphasis on gene transfer to beta cells, may enable us to study and dissect the role of key genes in islet physiopathology during the onset and development of diabetes.

The genetic engineering of different cell types has been achieved in vivo using non-viral and viral vectors. Nonviral vectors, like plasmids, allow the delivery of transgenes to target tissues through physical methods, but usually provide short-term expression [2]. Viral vectors exploit the natural ability of viruses to infect a certain cell type and deliver genes into the nucleus. In recombinant vectors, viral genes have been removed to avoid replication, enabling genes of interest to be introduced. Lentiviral vectors integrate into the host genome and can be used for chronic expression [3]. If integration is not desirable, nonintegrative vectors like adenovirus or adeno-associated virus (AAV), which can infect quiescent and dividing cells, may be used [3]. However, first-generation adenoviral vectors mediate short-term transgene expression due to their high immunogenicity [4]. Conventional AAV vectors contain a single-stranded (ss) DNA genome with a cloning capacity of $4.5 \mathrm{~kb}$, remain episomal and are able to mediate long-term transgene expression because of their lack of pathogenicity and low immunogenicity [5]. In addition, AAV vectors have been engineered to contain a doublestranded (ds) DNA genome (dsAAV) to circumvent synthesis of the complementary strand of DNA, a requisite for transgene expression in conventional ssAAV [6].

Despite the progress in in vivo tissue engineering, effective gene transfer to the pancreas has remained elusive due to its anatomic location and complex structure, with the risk of pancreatitis being a serious concern. Systemic administration of DNA-phospholipid gas-filled microbubbles in combination with ultrasound technology achieved short-term transduction of rat beta cells [7]. However, this technology is not broadly available and difficult to manage. Systemic delivery of first-generation adenoviral vectors with clamped hepatic circulation resulted in preferential but short-term transduction of beta cells [8, 9]. Lentiviral vectors delivered intraductally were able to transduce ductal and acinar cells, but only a minimal percentage of endocrine cells $[10,11]$. Conversely, AAV vectors have been described to be more efficient than adenoviral and lentiviral vector transducing of the pancreas [12, 13]. ssAAV vectors of serotype 8 and 9 (AAV8 and AAV9) have shown modest transduction of exocrine and endocrine pancreas when delivered systemically [14, 15], intrapancreatically [12, 13], intraductally [16] or through the intrapancreatic vessels [17]. In contrast to ssAAV, the use of dsAAV of serotypes 6 and 8 resulted in higher beta cell transduction [18]. However, a major restriction to the use of dsAAV is their very low cloning capacity of no more than $2.2 \mathrm{~kb}$ and difficulties in vector generation, which preclude transfer of many genes of interest to the pancreas.

Here, we performed a detailed comparative study of the ability of ssAAV of serotypes 6,8 and 9 to transfer genes to the pancreas in vivo, focused especially on beta cell transduction. Our results demonstrate that intraductal delivery of ssAAV vectors of serotypes 6,8 and 9 led to highly efficient and long-term transduction of beta cells and exocrine pancreas. Moreover, the use of specific pancreatic gene promoters restricted AAV-mediated transgene expression to acinar and/or beta cells. Finally, as proof of concept, intraductal delivery of AAV9 encoding for hepatocyte growth factor (HGF) prevented autoimmune diabetes in a mouse model of type 1 diabetes. Our results demonstrate the value of intraductal delivery of SsAAV vectors as a tool for genetic engineering in the pancreas for the study of islet physiopathology and assessment of new gene therapy approaches for diabetes.

\section{Methods}

Animals We used 8-week-old male CD1 mice for tropism and biodistribution analysis, rat insulin promoter (RIP)-I/ Ifn $\beta$ (also known as Ifnbl) transgenic CD1 mice [19] to assess prevention of diabetes and RIP-I/Igf-II (also known as Ifg2) transgenic mice [20] as a positive control of pancreatic Igf-II expression. Mice had free access to a standard diet (Teklad Global; Harlan Teklad, Madison, WI, USA) and were kept under a $12 \mathrm{~h}$ light-dark cycle (lights on at 08:00 hours). For diabetes induction, RIP-I/Ifn $\beta$ transgenic mice received five intraperitoneal injections, on consecutive days, of streptozotocin $(20 \mathrm{mg} / \mathrm{kg})$ dissolved in $0.1 \mathrm{~mol} / 1$ citrate buffer ( $\mathrm{pH} 4.5$ ). Blood glucose levels were assessed using an analyser (Glucometer Elite; Bayer, Leverkusen, Germany) and animals were considered diabetic after two consecutives measurements of glycaemia $\geq 14 \mathrm{mmol} / \mathrm{l}$. Animal care and experimental procedures were approved by the Ethics Committee in Animal and Human Experimentation of the Universitat Autònoma de Barcelona. 
Recombinant $A A V$ vectors Vectors were generated by triple transfection of human embryonic kidney 293 cells according to standard methods [21]. Cells were cultured to $80 \%$ confluence in ten roller bottles $\left(850 \mathrm{~cm}^{2}\right.$, flat; Corning, New York, NY, USA) in DMEM 10\% (vol./vol.) FBS and co-transfected by calcium phosphate method with a plasmid carrying the expression cassette flanked by the AAV2 inverted terminal repeats, a helper plasmid carrying the AAV rep and cap genes (serotypes 6, 8 and 9) and a plasmid carrying the adenovirus helper functions (all plasmids kindly provided by K.A. High, Children's Hospital of Philadelphia, Philadelphia, PA, USA). Transgenes used were: (1) eGFP driven by (a) the hybrid cytomegalovirus enhancer/chicken beta-actin constitutive promoter (CAG) and the Woodchuck hepatitis virus posttranscriptional regulatory element (WPRE), (b) the RIP-II or (c) the rat elastase I $(-205 /+8)$ promoter (kindly provided by $\mathrm{R}$. McDonald, University of Texas Southwestern Medical Center, Dallas, TX, USA); (2) murine Igf-II cDNA driven by the RIP-I and WPRE; and (3) murine $H g f$ cDNA driven by the cytomegalovirus constitutive promoter (CMV). A non-coding plasmid carrying the CMV promoter and a multicloning site (pAAV-MCS; Stratagene, La Jolla, CA, USA) was used to produce null particles. AAVs were purified with an optimised method based on a polyethylene glycol precipitation step and two consecutive caesium chloride $(\mathrm{CsCl})$ gradients [22]. This second-generation $\mathrm{CsCl}$-based protocol dramatically reduces empty AAV capsids and DNA and protein impurities from the viral stock, thus increasing AAV purity and ultimately resulting in higher transduction in vivo [22]. Purified AAV vectors were dialysed against $\mathrm{PBS}$, filtered and stored at $-80^{\circ} \mathrm{C}$. Titres of viral genomes (vg) were determined by quantitative PCR following the protocol described for the AAV2 Reference Standard Material using linearised plasmid DNA as standard curve [23].

In vivo administration of $A A V$ vectors Retrograde pancreatic intraductal injections were performed as described previously [16] with minor modifications. Mice were anaesthetised with ketamine $(100 \mathrm{mg} / \mathrm{kg})$ and xylazine (10 $\mathrm{mg} / \mathrm{kg})$. The duodenum was isolated with the common bile duct attached. A microclamp was placed on the bile duct caudal to the liver and a 30-gauge needle was used to advance retrogradely through the sphincter of Oddi into the common bile duct. The needle was secured in place with a second microclamp around the bile duct and $100 \mu \mathrm{AAV}$ was injected into the duct over approximately $1 \mathrm{~min}$. At $1 \mathrm{~min}$ post-injection the microclamps and needle were removed. For systemic administration, $200 \mu \mathrm{AAV}$ was injected via tail vein. No animals were lost due to surgical or post-surgical complications.
Immunohistochemistry Tissues were fixed for 12 to $24 \mathrm{~h}$ in $10 \%$ (wt/vol.) formalin, embedded in paraffin and sectioned. Immunohistochemical detection of green fluorescent protein (GFP), IGFII, glucagon, insulin, murine HGF and Ki67 was performed as indicated in electronic supplementary material (ESM), Methods.

Quantification of transduction Detection of GFP was performed in three pancreas sections per animal (three to four animals/group; sections $200 \mu \mathrm{m}$ apart). The percentage of transduced islets was calculated by dividing the number of $\mathrm{GFP}^{+}$islets by total islets of the pancreas section. Islets were deemed positive when at least one cell produced GFP. The percentage of transduced beta and alpha cells per islet was calculated by dividing the number of all double insulin ${ }^{+}$and $\mathrm{GFP}^{+}$cells or glucagon ${ }^{+}$and $\mathrm{GFP}^{+}$cells in one islet by the number of all insulin ${ }^{+}$or glucagon ${ }^{+}$cells of that islet, respectively. Quantification of transduction of the exocrine pancreas was performed in ten random fields per section. The transduced exocrine area and total area of each field were determined by image analysis with a microscope (Eclipse E800; Nikon, Tokyo, Japan) connected to a video camera and an image analyser (analySIS 3.0; Soft Imaging System, Center Valley, PA, USA). The percentage of transduced exocrine pancreas was calculated by dividing the transduced exocrine area by the total exocrine area.

Beta cell replication and apoptosis Beta cell proliferation and death rates were assessed as indicated in the ESM.

Histopathology Beta cell area and insulitis assessment were determined as indicated in the ESM.

Measurement of serum murine HGF concentration Circulating murine $\mathrm{HGF}$ levels were determined from serum samples with a mouse HGF Elisa kit (RayBiotech, Norcross, GA, USA). The sensitivity of this assay is $100 \mathrm{pg} / \mathrm{ml}$.

Statistical analysis All values are expressed as the means \pm SEM. Differences between groups were compared by unpaired Student's $t$ test. A $p$ value of $p<0.05$ was considered statistically significant.

\section{Results}

Pancreatic intraductal delivery of $A A V 6$ and AAV8 vectors transduces the endocrine pancreas more efficiently than AAV9 vectors To assess the transduction efficiency of the endocrine pancreas in vivo, three doses $\left(3 \times 10^{10}, 3 \times 10^{11}\right.$ and $3 \times 10^{12} \mathrm{vg}$ per mouse) of AAV vectors of serotype 6 , 
8 and 9 encoding the eGFP driven by the ubiquitous promoter CAG were delivered to the pancreas by retrograde pancreatic intraductal injection. At 1 month after the injection, expression of the marker gene in the islets of Langerhans was observed with all serotypes, albeit with different efficiencies depending on the serotype and dose injected. AAV6 and AAV8 transduced a higher number of islets at all the doses tested compared with AAV9, achieving transduction of all islets within the pancreas at a dose of $3 \times 10^{12} \mathrm{vg} /$ mouse (Fig. 1a).

Double immunostaining for insulin and GFP confirmed that beta cells were the main cell type transduced within the islet. At doses of $3 \times 10^{10}$ and $3 \times 10^{11} \mathrm{vg} /$ mouse, $\mathrm{GFP}^{+}$beta cells were located predominantly in the periphery of the

\section{a}
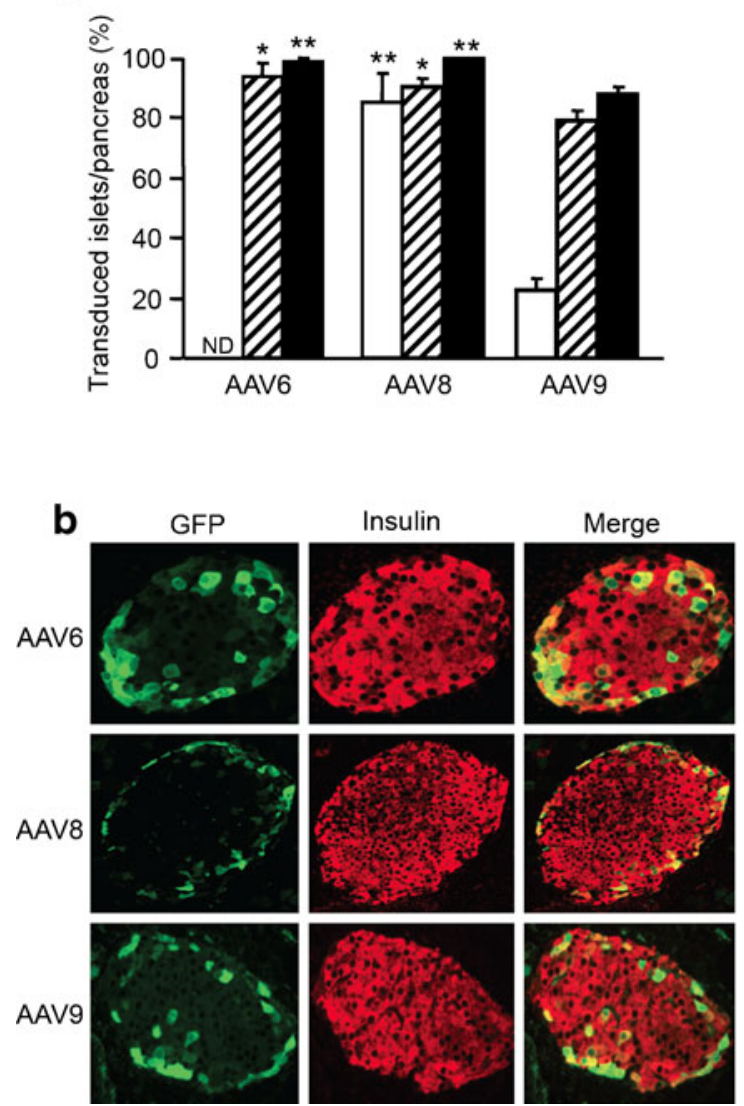

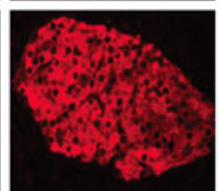

Fig. 1 Transduction of beta cells by AAV vectors delivered intraductally. Mice were injected intraductally with $3 \times 10^{10}$ (white bars), $3 \times 10^{11}$ (hatched bars) and $3 \times 10^{12}$ (black bars) vg of AAV6, AAV8 and AAV9 encoding the GFP reporter gene driven by the CAG ubiquitous promoter. Animals were analysed 1 month after injection. a Quantification of transduced islets per pancreas (\%). Results are expressed as mean $\pm \mathrm{SEM} ; n=3-4$ animals per group. ND, not determined. b Immunohistochemical analysis of GFP (green) and insulin (red) abundance in islets of animals injected with $3 \times 10^{11} \mathrm{vg}$ of AAV6, AAV8 and AAV9. Transduced beta cells were located islets (Fig. $1 b$ and data not shown), whereas at a dose of $3 \times$ $10^{12} \mathrm{vg} /$ mouse transduced beta cells were found in the periphery and the core (Fig. 1c). Quantification of the number of $\mathrm{GFP}^{+}$beta cells demonstrated similar transduction efficiency for AAV6 and AAV8, and revealed that these serotypes were more efficient than AAV9 in transducing beta cells (Fig. 1d). On average about $45 \%$ of beta cells within islets were transduced by AAV6 and AAV8 at a dose of $3 \times 10^{12} \mathrm{vg} /$ mouse (Fig. 1d). Interestingly, no decline in GFP levels in beta cells was observed at 3 and 6 months after intraductal administration of AAV8-CAGGFP vectors (ESM Fig. 1a).

Double immunostaining for glucagon and GFP showed that the percentage of islets per pancreas with transduced

\section{d}
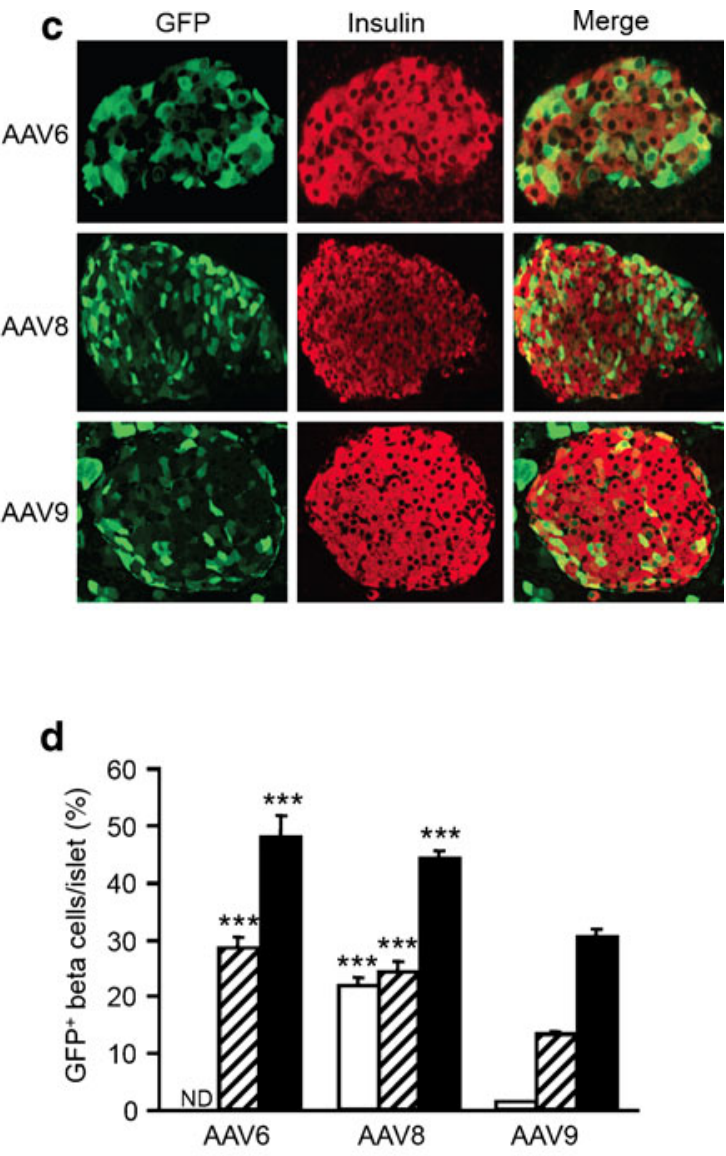

preferentially at the islet periphery. c Immunohistochemical analysis of GFP (green) and insulin (red) abundance in islets of mice injected with $3 \times 10^{12} \mathrm{vg}$ of AAV6, AAV8 and AAV9. Transduced beta cells were located in the periphery and core of islets. Original magnification $(\mathbf{b}, \mathbf{c}) \times 200($ AAV8) and $\times 400($ AAV6 and AAV9). d Quantification of transduced beta cells per islet (\%). AAV6 and AAV8 vectors were more efficient than AAV9 vectors in transducing beta cells. Results are expressed as mean \pm SEM; $n=100$ islets per animal, $n=3-4$ animals per group. ${ }^{*} p<0.05,{ }^{* *} p<0.01$ and ${ }^{* * *} p<0.001$ vs AAV9 at the same dose. ND, not determined 
alpha cells (Fig. 2a) was lower than the number of islets with $\mathrm{GFP}^{+}$beta cells (Fig. 1a). Moreover, alpha cells were poorly transduced by AAV6, AAV8 and AAV9 at the three doses tested (Fig. $2 \mathrm{~b}$ and data not shown). Similarly to findings with beta cells, quantification of the number of $\mathrm{GFP}^{+}$alpha cells revealed that AAV6 and AAV8 transduced this cell type more efficiently than AAV9 (Fig. 2c).

Pancreatic intraductal delivery of AAV6, AAV8 and AAV9 vectors transduces the exocrine pancreas The transduction efficiency of the exocrine pancreas in vivo as mediated by AAV6, AAV8 and AAV9 vectors was also examined. At 1 month post-injection, immunohistochemical staining for GFP revealed efficient and widespread transduction of the acinar cells with all the serotypes and doses tested (Fig. 3a and data not shown). However, transduction of ductal cells was only observed when AAV6 vectors were administered (Fig. 3b). Quantification of the transduced exocrine area showed similar transduction efficiencies for AAV6, AAV8 and AAV9 at doses of $3 \times 10^{10}$ and $3 \times 10^{11} \mathrm{vg} /$ mouse. At a dose of $3 \times 10^{12} \mathrm{vg} /$ mouse, improved gene transfer to the exocrine pancreas was achieved by AAV9 in comparison with AAV6. A similar tendency was observed for AAV8, although the difference did not reach statistical significance (Fig. 3c). GFP production was detected in acinar cells of the pancreas for at least 6 months after injection of AAV8CAG-GFP vectors (ESM Fig. 1b).

Use of different pancreatic promoters to direct the expression of genes of interest to specific cell types Given that the GFP production cassette was driven by the CAG ubiquitous promoter, targeting of non-pancreatic tissues after intraductal delivery of AAV6, AAV8 and AAV9 vectors was assessed. Transgene expression was not detected in the kidney, lung, spleen and intestine (data not shown). However, transduction of hepatocytes located around central venules was found in animals treated with $3 \times 10^{10}, 3 \times 10^{11}$ and $3 \times 10^{12} \mathrm{vg} /$ mouse of AAV8 and AAV9 (ESM Fig. 2a and data not shown). Additionally, AAV8 at the highest dose, and AAV9 at $3 \times 10^{11}$ and $3 \times 10^{12} \mathrm{vg} /$ mouse were able to transduce the heart (ESM Fig. 2b), although with lower efficiency than the liver. GFP production was completely undetectable in liver and heart of animals treated with AAV6 (data not shown).

To achieve AAV-mediated transgene expression in specific cell types of the pancreas, tissue-specific promoters are required. RIP-I was used to restrict transgene expression to beta cells. At 1 month after pancreatic intraductal injection of $1 \times 10^{12} \mathrm{vg}$ of AAV8 encoding murine IGF-II driven by the RIP-I promoter, IGF-II production was
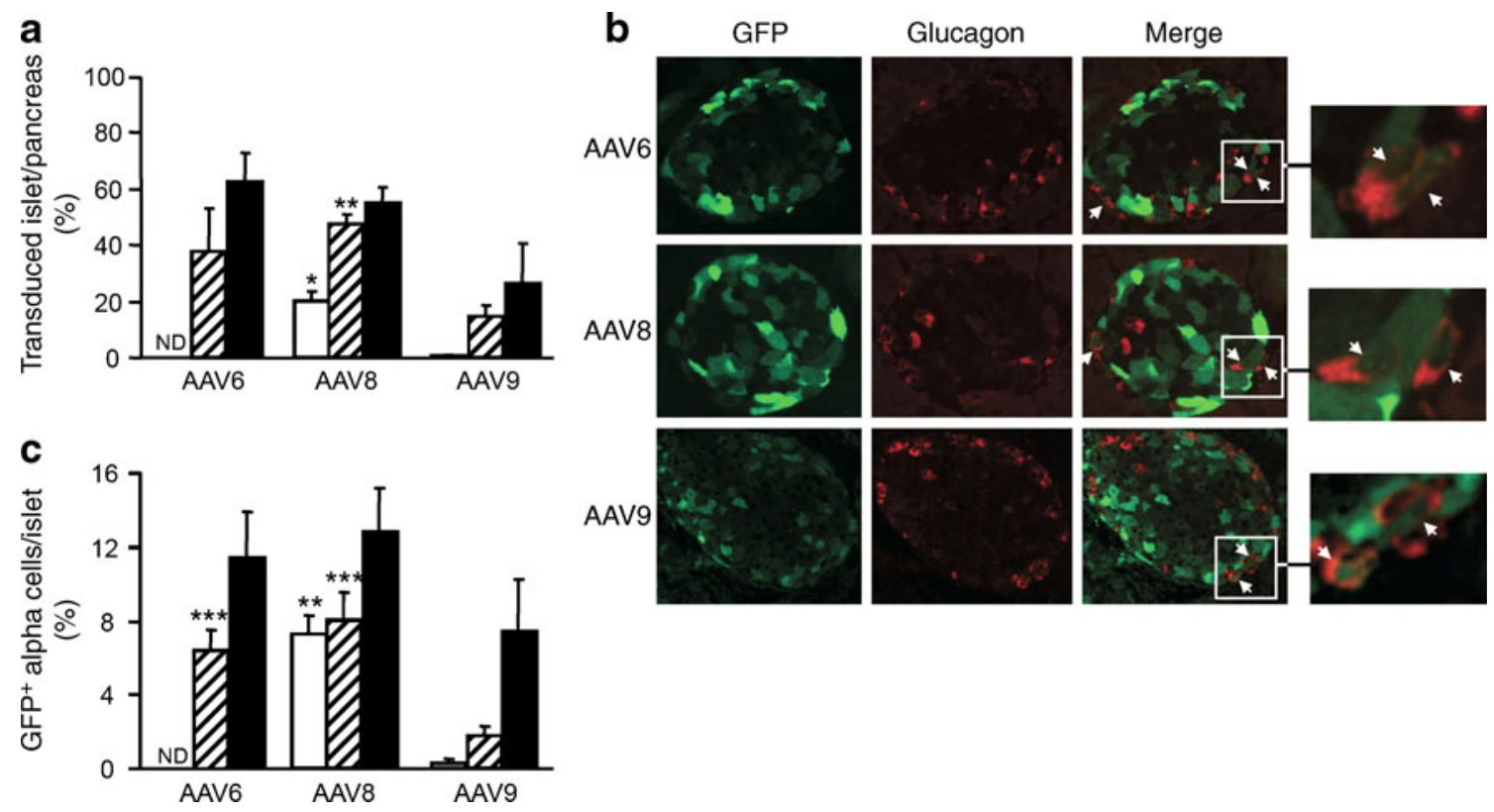

Fig. 2 Transduction of alpha cells by AAV vectors delivered intraductally. a Quantification of islets with transduced alpha cells per pancreas $(\%)$ in mice injected intraductally with $3 \times 10^{10}$ (white bars), $3 \times 10^{11}$ (hatched bars) and $3 \times 10^{12}$ (black bars) vg of AAV6, AAV8 and AAV9-CAG-GFP. Quantification was done 1 month after injection. ND, not determined. Results are expressed as mean $\pm \mathrm{SEM}$; $n=3-4$ animals per group. b Immunohistochemical analysis of GFP (green) and glucagon (red) production in islets of mice injected with
$3 \times 10^{12} \mathrm{vg}$ of AAV6, AAV8 and AAV9. Transduction of only a few alpha cells was achieved (arrows). Original magnification $\times 200$ (AAV9) and $\times 400$ (AAV6 and AAV8). c Quantification of transduced alpha cells per islet (\%). AAV6 and AAV8 were more efficient than AAV9 vectors in transducing alpha cells. Results are expressed as mean \pm SEM; $n=100$ islets/animal, $n=3-4$ animals per group. ${ }^{*} p<$ $0.05, * * p<0.01$ and $* * * p<0.001$ vs AAV9 at the same dose. ND, not determined 
a
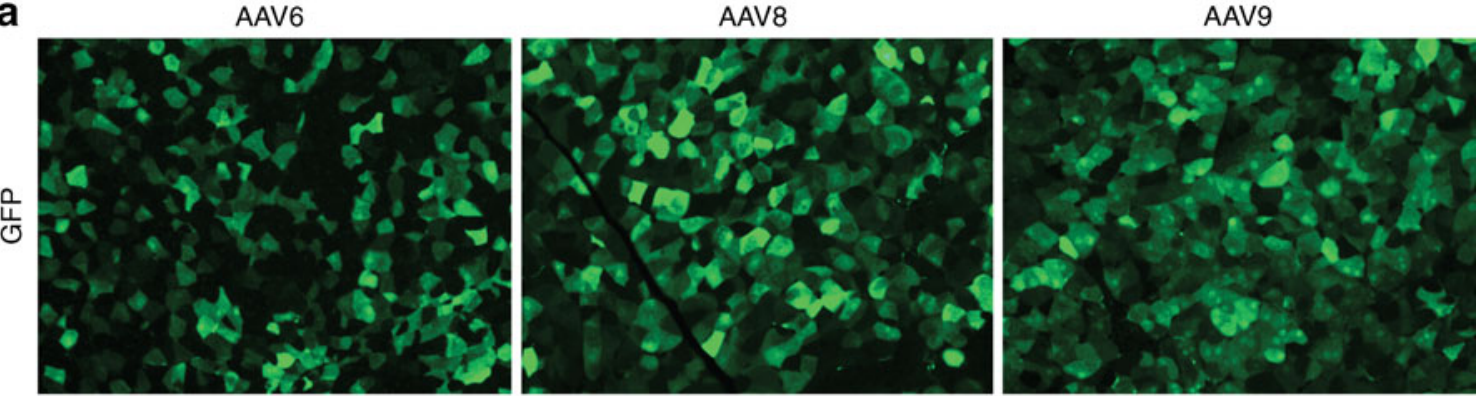

b

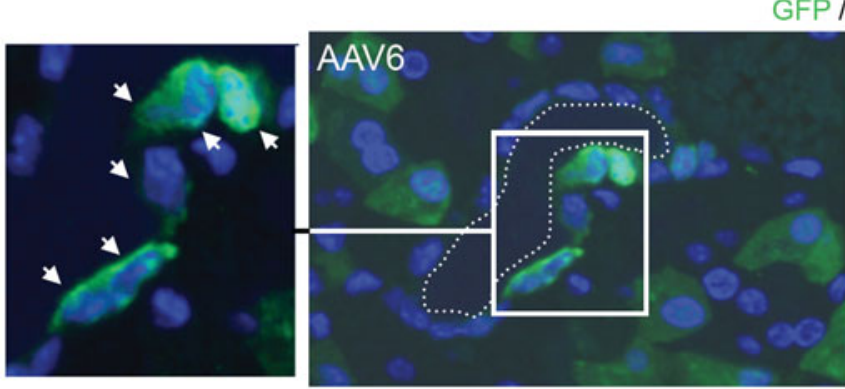

GFP / Nuclei
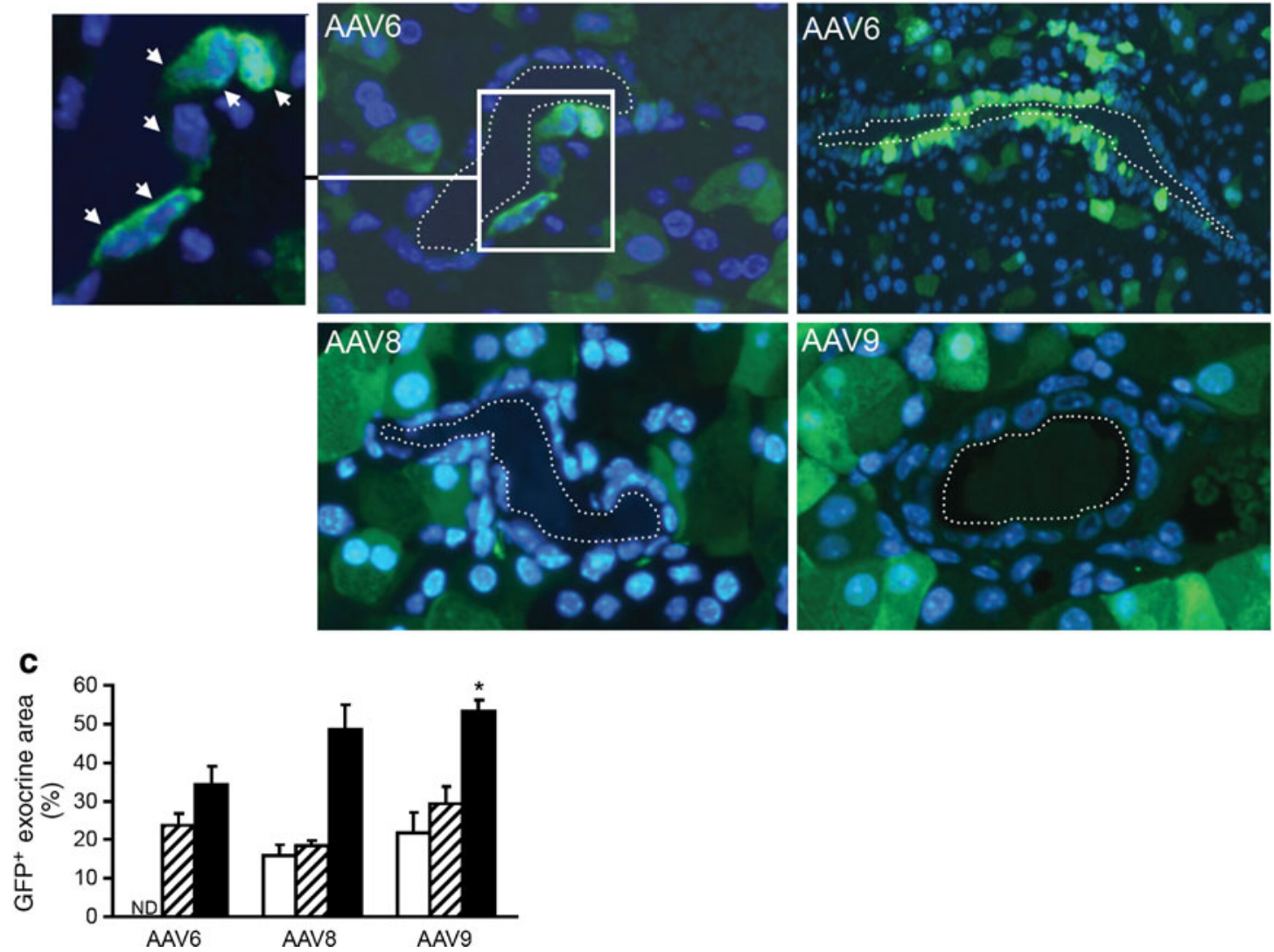

Fig. 3 Transduction of the exocrine pancreas by AAV vectors delivered intraductally. a Representative images of transduced acinar cells producing GFP (green) in mice injected intraductally with $3 \times$ $10^{12} \mathrm{vg}$ of AAV6, AAV8 and AAV9 at 1 month after injection. Original magnification $\times 200$. b Immunohistochemical analysis of GFP (green) showed transduction of ductal cells by AAV6 vectors at doses of $3 \times 10^{11}$ (inset and left panel) and $3 \times 10^{12}$ (right panel) $\mathrm{vg}$, and absence of ductal transduction by AAV8 and AAV9 at $3 \times 10^{12} \mathrm{vg}$.

Arrows indicate transduced ductal cells. Original magnification $\times 200$ (AAV6 $3 \times 10^{12} \mathrm{vg}$ ) and $\times 400\left(\right.$ AAV6 $3 \times 10^{11} \mathrm{vg}$, AAV8, AAV9). c Quantification of the percentage of transduced exocrine area in mice injected intraductally with $3 \times 10^{10}$ (white bars), $3 \times 10^{11}$ (hatched bars) and $3 \times 10^{12}$ (black bars) vg of AAV6, AAV8 and AAV9-CAG-GFP vectors. Results are expressed as mean \pm SEM; $n=3-4$ animals per group. ${ }^{*} p<0.05$ vs AAV6 at the same dose. ND, not determined

detected in the periphery and core of the islets. This IGF-II production pattern was similar to that observed in a transgenic animal model that expresses Igf-II specifically in beta cells (RIP-I/Igf-II transgenic mouse [20]), although at lower levels (Fig. 4a). Double immunostaining for insulin and IGF-II confirmed that AAV-mediated IGF-II production was restricted to beta cells (Fig. 4b). Likewise, the intraductal delivery of $3 \times 10^{11} \mathrm{vg} /$ mouse of AAV9 vectors carrying the
eGFP gene driven by the RIP-II also resulted in specific expression of the marker gene in beta cells (ESM Fig. 3a) without any detection of GFP in exocrine pancreas, liver or heart (ESM Fig. 3b).

In addition, we explored the use of the rat elastase I $(-205 /+8)$ promoter. This modified version of the promoter has been reported to mediate high expression in acinar cells, but minimal expression in beta cells of 


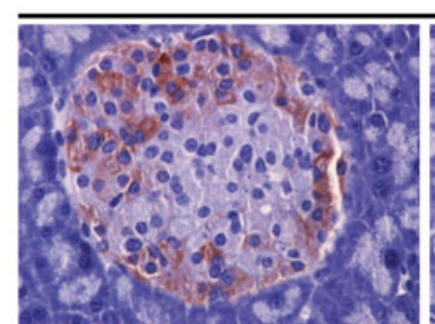

AAV8 RIP-I/lgfll

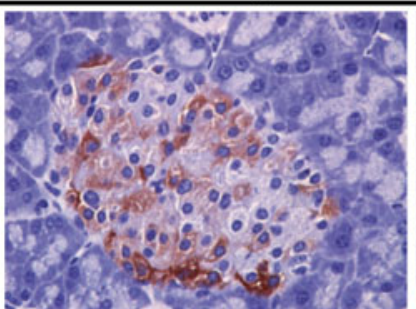

Tg RIP-I/IgfII
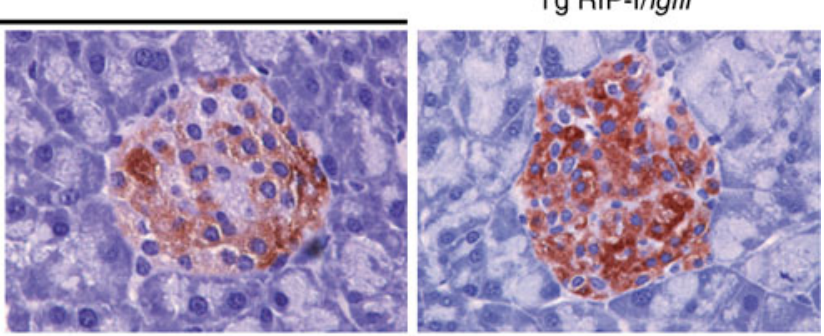

b
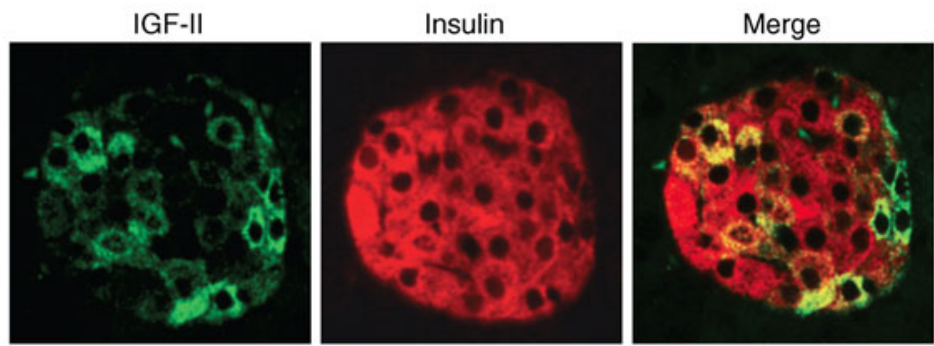

AAV8-(-205/+8)Elastase-GFP

C

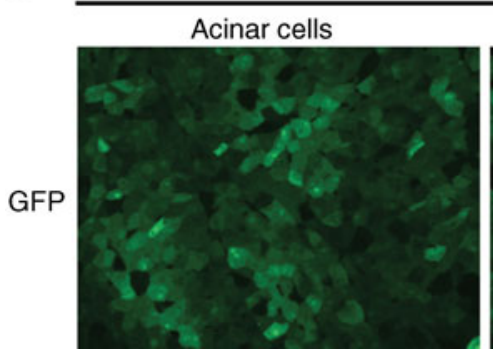

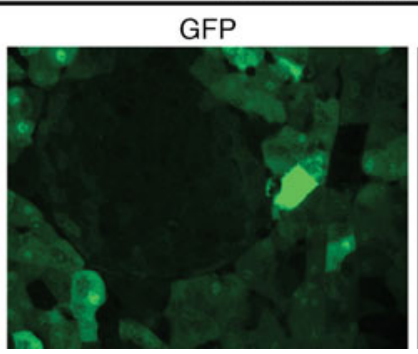
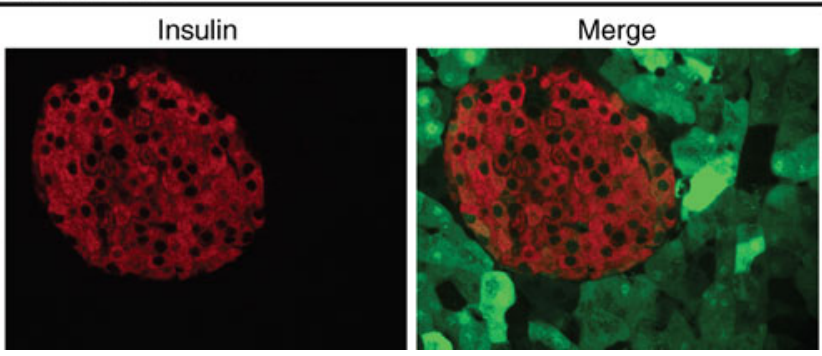

Fig. 4 Use of pancreas-specific promoters to drive AAV-mediated transgene expression to specific cell types. a AAV-mediated transgene expression in beta cells. The intraductal injection of $10^{12} \mathrm{vg}$ of AAV 8 vectors encoding IGF-II driven by the RIP-I promoter restricted production of IGF-II (brown) to islets, with a similar pattern to that observed in a beta cell-specific transgenic model (RIP-I/Igf-II). Original magnification $\times 400$. b Immunohistochemical detection of IGF-II (green) and insulin (red) in islets of mice injected with $10^{12} \mathrm{vg}$

transgenic mice $[24,25]$. Due to the poor expression penetrance in beta cells observed with this promoter in transgenic mice $[24,25]$, a very high dose $\left(2 \times 10^{13} \mathrm{vg} /\right.$ mouse) of AAV8-(-205/+8)elastase-GFP vectors was administered intraductally to maximise transgene expression in beta cells. At 1 month after injection, acinar cells showed strong GFP production, whereas low transgene expression was found in beta cells (Fig. 4c). No GFP was detected in alpha cells, liver or heart (data not shown), indicating strong specificity of the promoter despite the high dose of vectors delivered.

Systemic delivery of AAV8 and AAV9 vectors leads to low transduction of the pancreas compared with intraductal administration To assess the pancreatic transduction efficiency of AAV8 and AAV9 vectors injected systemically, $5 \times 10^{12} \mathrm{vg} /$ mouse of AAV8 and AAV9-CAG-GFP were administered via tail vein. At 1 month post-injection, the of AAV8-RIP-I/Igf-II revealed that IGF-II production was restricted to beta cells. Original magnification $\times 400$. c AAV-mediated transgene expression specifically in beta and acinar cells. Immunohistochemical analysis of GFP (green) showed high transduction of acinar cells, but low transgene expression in beta cells at 1 month after intraductal delivery of $2 \times 10^{13} \mathrm{vg}$ of AAV8 vectors encoding GFP driven by the elastase promoter. Original magnification $\times 200$ (Acinar) and $\times 400$ (other panels)

percentage of transduced islets observed with either serotype (Fig. 5a) with this route of delivery was lower than that obtained after intraductal administration of the same vectors (Fig. 1a). Double immunostaining for GFP and insulin revealed that transduction of beta cells was randomly distributed within the islet (Fig. 5b), whereas alpha cells were barely transduced (data not shown). Quantification of $\mathrm{GFP}^{+}$beta cells revealed that AAV8 and AAV9 presented a similar transduction efficiency of the endocrine pancreas (about 18\% transduced beta cells per islet) when administered systemically at high dose (Fig. 5c), but this was considerably less than the efficiency observed after intraductal delivery (Fig. 1d). Systemic delivery of AAV8 and AAV9 also resulted in low gene transfer to the exocrine pancreas (Fig. 5d, e). Systemic delivery of AAV vectors therefore resulted in less efficient transduction of endocrine and exocrine pancreas than intraductal administration. 

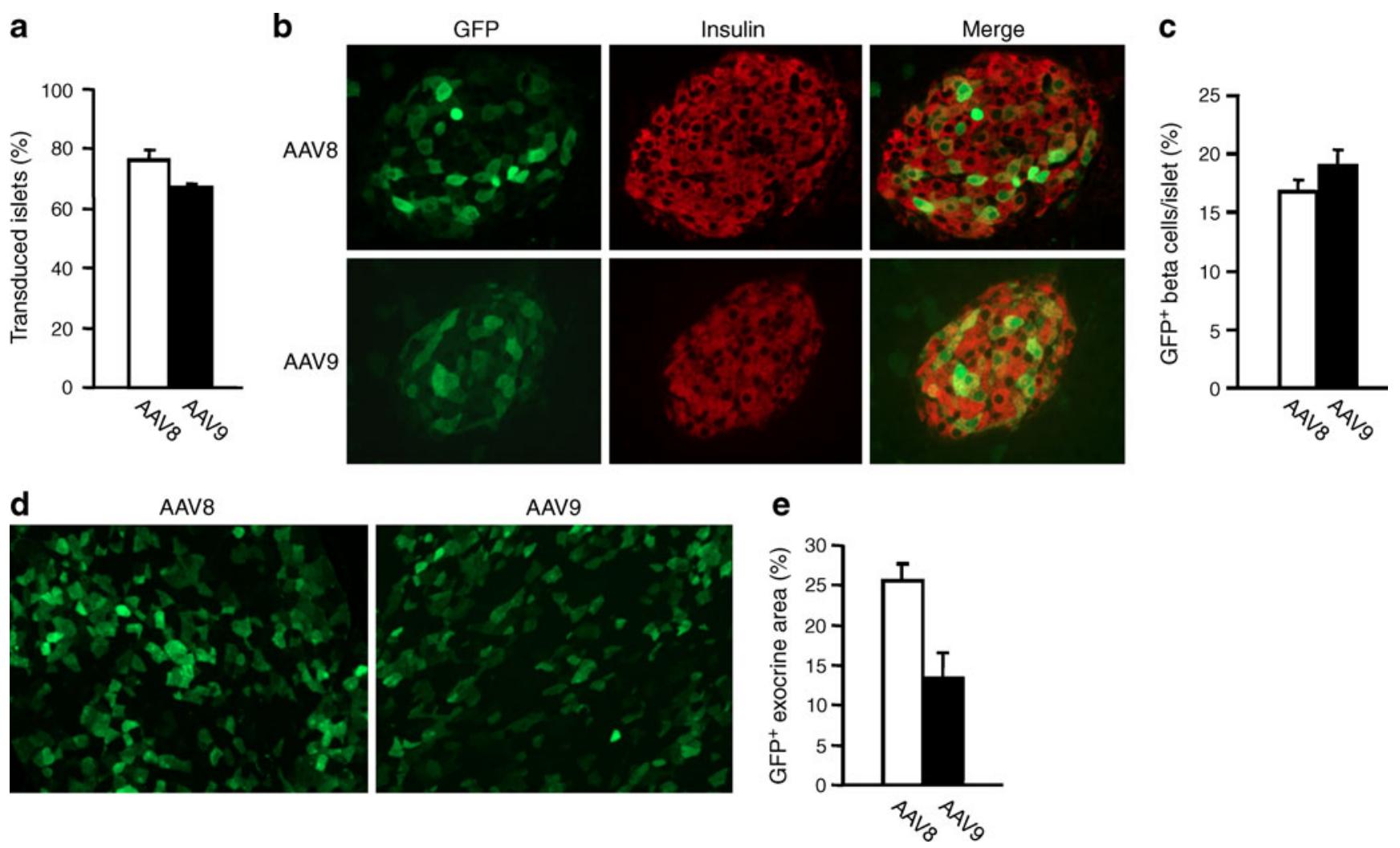

Fig. 5 Pancreatic transduction after systemic delivery of AAV vectors. Mice were injected systemically with $5 \times 10^{12}$ vg of AAV8 and AAV9-CAG-GFP vectors and pancreas transduction was analysed 1 month after injection. a Quantification of transduced islets per pancreas (\%). Results are expressed as mean \pm SEM; $n=3$ animals per group. b Immunohistochemical analysis of GFP (green) and insulin (red). Transduced beta cells were located randomly within the islets. Original magnification $\times 400$. c Quantification of transduced

Intraductal delivery of AAV9-murine HGF prevents autoimmune diabetes HGF is a beta cell mitogen and prosurvival factor. Beta cells of transgenic mice expressing $H g f$ specifically in beta cells $[26,27]$ or murine and non-human primate islets transduced in vitro with adenoviral vectors encoding HGF and then transplanted into diabetic mice [28-30] displayed improved function, increased proliferation and reduced cell death.

To examine whether in vivo AAV-mediated gene transfer of $\mathrm{Hgf}$ to the pancreas prevented the development of autoimmune diabetes, $3 \times 10^{11} \mathrm{vg} /$ mouse of AAV9 encoding the murine HGF driven by the CMV promoter (AAV9mHGF) was intraductally delivered to adult RIP-I/Ifn $\beta$ transgenic mice. These mice, when treated with very low doses of streptozotocin that do not affect wild-type mice, develop autoimmune diabetes similar to type 1 diabetes in humans, with marked mononuclear infiltration of islets and presence of $\mathrm{CD}^{+}$and $\mathrm{CD} 8^{+} \mathrm{T}$ cells [19]. Control RIP-I/Ifn $\beta$ transgenic mice received the same dose of AAV9 null vectors, which retained equal infectivity but beta cells per islet (\%). Both vectors showed similar beta cell transduction efficiency. Results are expressed as mean \pm SEM; $n=100$ islets per animal, $n=3$ animals per group. d Immunohistochemical analysis of GFP (green) showing transduction of acinar cells after systemic administration of AAV8 and AAV9 vectors. Original magnification $\times 200$. e Quantification of transduced exocrine area (\%). Results are expressed as mean \pm SEM; $n=3$ animals per group

did not carry any transgene. Two weeks after AAV administration, animals were treated with five consecutive injections of low-dose streptozotocin $(5 \times 20 \mathrm{mg} / \mathrm{kg})$ to trigger the diabetic process [19]. Analysis of the individual glycaemic profiles revealed that whereas most of the animals injected with AAV9-null vectors became hyperglycaemic (Fig. 6a), the majority of animals treated with AAV9-mHGF remained normoglycaemic (Fig. 6b). Consequently, treatment with AAV9-mHGF significantly reduced the incidence of autoimmune diabetes in RIP-I/ Ifn $\beta$ transgenic mice (Fig. 6c). Immunostaining against murine HGF at 52 days after injection revealed overabundance of this factor by numerous acinar and islet cells, and a negligible number of hepatocytes in animals receiving AAV9-mHGF vectors, but not in AAV9-null-treated animals (Fig. 6d, ESM Fig. 4). This suggests that prevention of diabetes is mediated by murine HGF produced locally in the pancreas. In agreement with this, no differences in circulating murine HGF levels were found between AAV9-

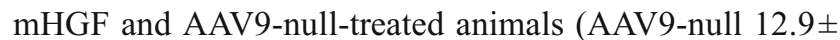



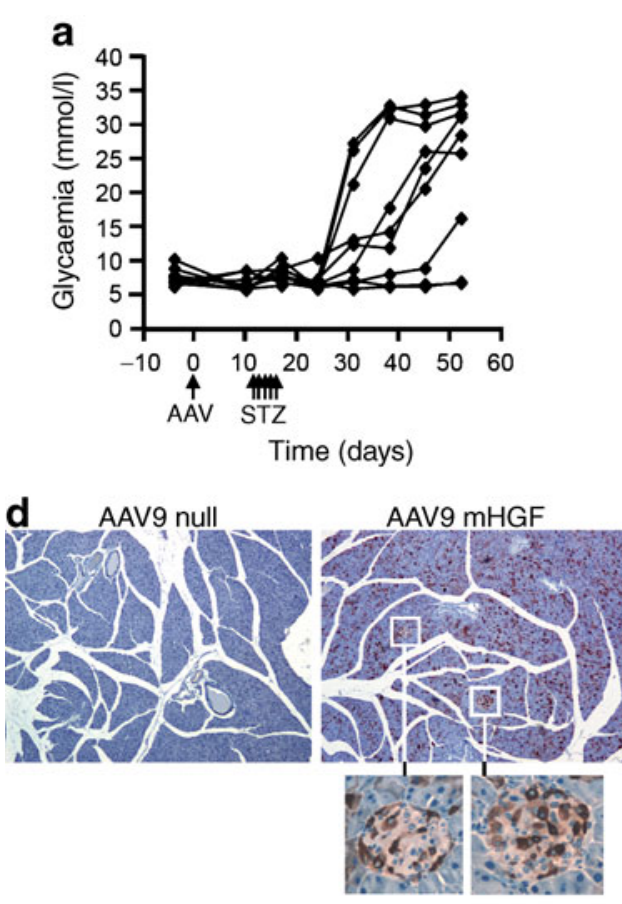
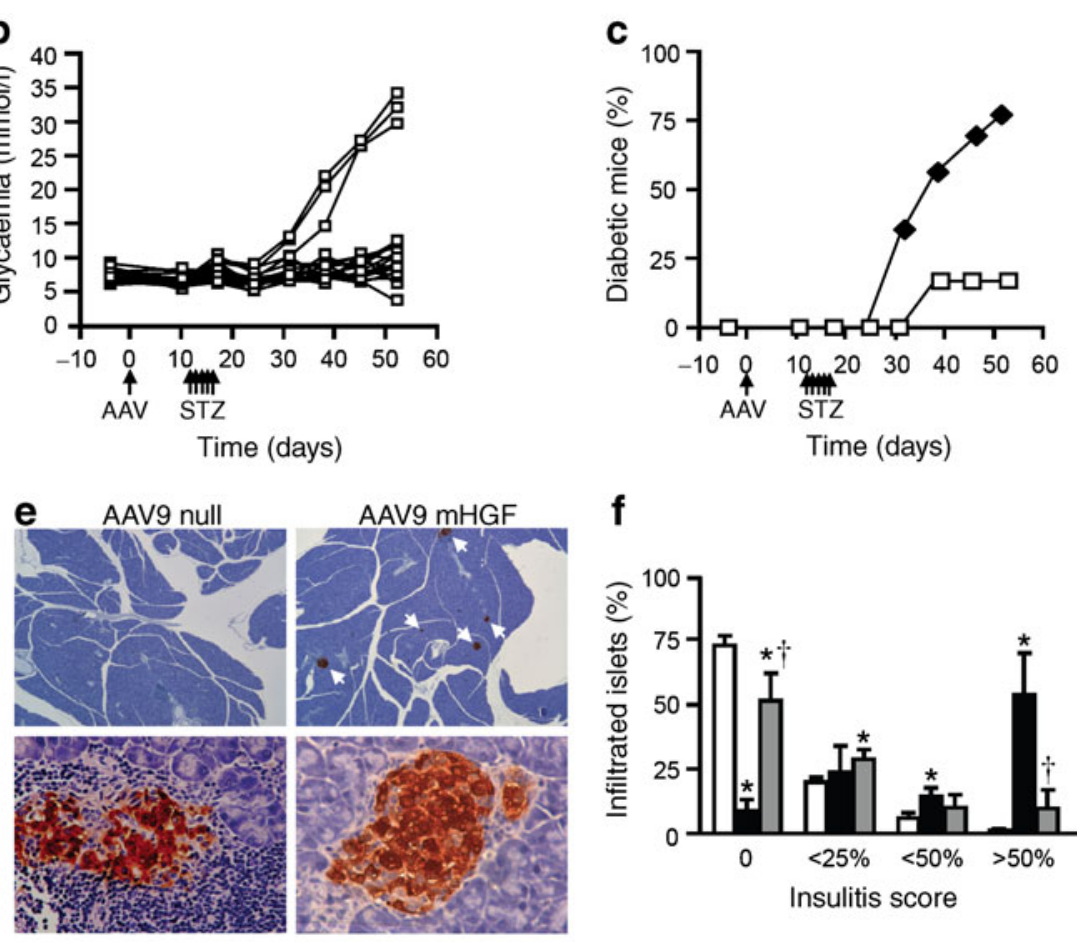

j

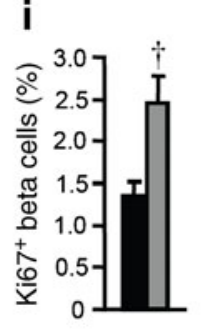

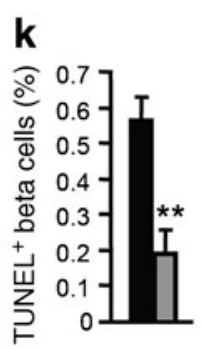

Fig. 6 Intraductal delivery of AAV9-mHGF protects RIP-I/Ifn $\beta$ mice from autoimmune diabetes. a Individual glycaemic profiles of RIP-I/Ifn $\beta$ mice injected intraductally with $3 \times 10^{11} \mathrm{vg}$ of AAV9 null vectors or (b) AAV9-mHGF vectors prior to streptozotocin treatment; (a) $n=9$ and (b) $n=17$. c Cumulative diabetes incidence after intraductal injection of AAV9 vectors and streptozotocin treatment. Mice were considered diabetic after two consecutives measurements of blood glucose $\geq 14 \mathrm{mmol} / \mathrm{l}$. Black symbols, AAV9 null; white symbols, AAV9-mHGF. d Immunohistochemical analysis of murine HGF (brown) in pancreas of AAV9 null and AAV9-mHGF-treated mice. Original magnification $\times 100$. e Insulin immunostaining (brown) 52 days after intraductal injection of AAV9 vectors. Arrows indicate islets. AAV9-null treated mice showed reduced number of islets and higher degree of insulitis compared with AAV9-mHGF treated mice. Original magnification $\times 100$ (top row) and $\times 400$. f Insulitis score was measured as indicated in Methods. Scores represented: no infiltration $(0)$, peri-insulitis $(<25 \%)$, moderate insulitis $(<50 \%)$ and severe insulitis $(>50 \%)$. Results are means \pm SEM; $n=5-6$ animals per group.

2.8, AAV9-mHGF $12.5 \pm 0.5 \mathrm{ng} / \mathrm{ml}$ ), further confirming an autocrine and paracrine protective effect of murine HGF on beta cells.

The histological analysis of pancreas sections showed islets with decreased infiltration as a result of HGF treatment (Fig. 6e). Quantification of the degree of insulitis revealed that about $90 \%$ of islets in AAV9-null-treated mice
White bars, non-streptozotocin; black bars, streptozotocin-AAV9-null; grey bars, streptozotocin-AAV9-mHGF. g Beta cell mass was measured after intraductal injection of AAV9-null or AAV9-mHGF in streptozotocin-treated and non streptozotocin-treated RIP-I/Ifn $\beta$ mice. Results are means \pm SEM. Key as above (f). h Beta cell replication was assessed by Ki67 immunostaining (green). Beta cells, red; nuclei, blue; arrows, $\mathrm{Ki}^{+} 7^{+}$beta cells. Original magnification $\times 400$. i Beta cell proliferation rate was determined as indicated in Methods. Results are means \pm SEM. Key as above (f). j Beta cell death was assessed by TUNEL analysis (green). Non-beta cells, red; nuclei, blue; arrows, TUNEL ${ }^{+}$beta cells. Original magnification $\times 400$. $\mathbf{k}$ Beta cell death rate was determined as indicated in Methods. Results are means \pm SEM. $\mathbf{d}-\mathbf{k}$ Analyses were performed 52 days post-injection of AAV9 vectors $(n=5$ for AAV9 null-treated mice, $n=6$ for AAV9mHGF-treated mice). ${ }^{*} p<0.05$ vs non-streptozotocin RIP-I/Ifn $\beta$ mice; ${ }^{\dagger} p<0.05$ vs AAV9 null-treated RIP-I/Ifn $\beta$ mice; $* * p<0.01$ vs AAV9 null-treated RIP-I/Ifn $\beta$ mice

showed lymphocytic infiltration, with more than $50 \%$ of islets severely infiltrated (Fig. 6f). In contrast, AAV9mHGF-treated animals showed a clear reduction in the degree of insulitis, which mainly consisted of peri-insulitis and resembled the pattern of insulitis observed in nonstreptozotocin-treated RIP-I/Ifn $\beta$ transgenic mice (Fig. 6f). This result was in parallel with the preservation of beta cell 
mass observed after HGF treatment (Fig. 6g). AAV9-nulltreated mice had decreased beta cell mass as a consequence of diabetes development, while AAV9-mHGF-treated animals showed similar beta cell mass to non-streptozotocintreated RIP-I/Ifn $\beta$ transgenic mice (Fig. $6 \mathrm{~g}$ ). Given that HGF has been shown to be a mitogenic and anti-apoptotic factor for beta cells [26-30], beta cell proliferation and death rates were assessed by Ki67 immunostaining and TUNEL analysis, respectively (Fig. 6h, j). AAV9-mHGFtreated animals showed an approximately twofold increase in the percentage of $\mathrm{Ki}^{+} 7^{+}$beta cells (Fig. 6i) and an approximately threefold decrease in the percentage of TUNEL $^{+}$beta cells (Fig. 6k) compared with AAV9-nulltreated mice. Collectively, these findings suggest that murine HGF may protect RIP-I/Ifn $\beta$ transgenic mice from autoimmune diabetes by preserving beta cell mass through a combination of enhanced beta cell proliferation and reduced beta cell death and insulitis.

\section{Discussion}

In this study we performed a detailed analysis of the ability of ssAAV6, 8 and 9 vectors to transduce the pancreas. Efficient and widespread transduction of beta and acinar cells was obtained by intraductal delivery of AAV6, AAV8 and AAV9, with long-term transgene expression in these cell types demonstrated for AAV8 and AAV9. In comparison to previous works in rodents injected with ssAAV [12-16], our results clearly demonstrate extensive and enhanced transduction of the pancreas in vivo, especially of beta cells. A team from our institution recently reported a novel optimised purification protocol for AAV vectors that dramatically reduces empty AAV capsids, as well as DNA and protein impurities from the viral stock [22]. High AAV vector purity achieved by this method resulted in serotypeand tissue-independent enhancement of transduction efficiency [22], and this may account for the high pancreatic transduction observed in the present study. Moreover, the pancreatic transduction efficiency obtained in the present study after intraductal injection of ssAAV was comparable to that reported for dsAAV, which has been described as having higher transduction efficiency than ssAAV in the pancreas [18]. Our study has also demonstrated superior gene transfer to the endocrine and exocrine pancreas by intraductal delivery of AAVs compared with systemic delivery, even when using 100-fold lower dose of vectors. This may reflect the local nature of intraductal administration, which minimises distribution of the vectors to the periphery, and their exposure and uptake by non-pancreatic organs. However, some transduction of the liver and heart was also found. This extrapancreatic expression of the gene of interest can be circumvented by use of RIP-I, RIP-II and elastase promoters to restrict AAV-mediated transgene expression to acinar and/or beta cells.

Conventional transgenic and knockout (KO) mouse models have been used to investigate the role of key genes in islet physiopathology during the onset and development of diabetes. However, the phenotype of these models could sometimes be open to debate, as most of the promoters (RIP-I, RIP-II, Pdx-1...) [31, 32] used to generate these animals drive expression of the transgene during embryonic development. To avoid transgene expression during the fetal phase, conditional and/or inducible transgenic/KO mice have been generated by Cre-Lox and/or tetracyclinedependent systems. However, these approaches are timeand cost-consuming. In contrast, intraductal delivery of AAV6, AAV8 and AAV9 may have great potential in genetic engineering of the pancreas to overexpress or knockdown (by transfer of siRNA/miRNA) genes of interest, with several advantages over transgenic/KO mouse models. For instance, AAV vector production requires a short period of time (a few weeks) and can be used in different animal models of diabetes (both small and large animal models). In addition, AAV vectors can be administered at different time-points during disease progression, allowing the study of different stages of the disease. Thus, intraductal delivery of AAV vectors could be a very attractive alternative to the use of transgenic/KO mice models, especially when high-throughput screening of genes is required. In this regard, the pattern of Igf-II expression achieved by intraductal delivery of AAV8 was similar to that shown by RIP-I/Igf-II transgenic animals. Although the partial transduction of the central core of the islets may represent a drawback in certain cases, the fact that AAV6 and AAV8 can transduce virtually every islet and that secreted factors expressed by transduced cells can act in neighbouring non-transduced cells may overcome this limitation in many applications.

As proof of principle, we tested whether AAV9-mediated delivery of $H g f$ by intraductal administration to RIP-I/Ifn $\beta$ transgenic mice protected them from autoimmune diabetes. Although not statistically significant, AAV9-CAG-GFP vectors at a dose of $3 \times 10^{11} \mathrm{vg}$ showed a tendency to transduce higher number of acinar cells than AAV6 and AAV8. Thus, AAV9 vectors were chosen for the proof-ofprinciple experiment in order to target beta cells as well as to maximise the number of acinar cells that would supply murine HGF to the non-transduced beta cells. In addition, to avoid substantial transduction of hepatocytes, we exploited the fact that intraductal administration of AAV9 resulted in lower transduction of hepatocytes than AAV8. In agreement with this strategy, high and widely distributed overabundance of murine HGF was detected in pancreas, but not in liver of AAV9-mHGF-treated mice. The increased pancreatic murine HGF levels mediated signifi- 
cant prevention of autoimmune diabetes with preservation of beta cell mass, increased beta cell proliferation, and decreased beta cell death and insulitis. Similar effects have been reported for elevated circulating levels of HGF when the liver of streptozotocin-treated mice was targeted [33, 34]. However, certain immunomodulatory effects of murine HGF cannot be completely ruled out, as HGF has been reported to protect rodent beta cells from cytokine-induced cell death [35] and HGF-mediated reduction of the number of infiltrating cells has also been described in others animal models of immune-mediated diseases [36-38].

In conclusion, we have demonstrated that retrograde intraductal delivery of ssAAV6, 8 and 9 vectors may be a useful tool for genetic engineering in the pancreas in vivo to study islet and pancreas physiopathology and also to assess new gene therapy approaches for diabetes. In addition, this approach provides a shortcut to the generation of relevant animal models of the disease. Importantly, the retrograde pancreatic intraductal injection can be performed in large animals and humans through a less invasive, nonsurgical clinical procedure called endoscopic retrograde cholangiopancreatography [39], opening the possibility for a future translation of successful treatments to humans.

Acknowledgements We thank V. Haurigot for helpful discussions, and M. Moya, X. Leon, M. Molas and D. Ramos for technical assistance. This work was supported by grants from Ministerio de Ciencia e Innovación, Plan Nacional I+D+I (SAF2008-00962) and Generalitat de Catalunya (2009 SGR-224), Spain, and from European Commission DG Research FP6 (CLINIGENE, LSHB-CT-2006018933). V. Jimenez and J. Agudo were recipients of predoctoral fellowships from Ministerio de Educación, Cultura y Deporte. C. Mallol is recipient of a predoctoral fellowship from Ministerio de Educación. A. Salavert received a predoctoral fellowship from Direcció General de Recerca, Generalitat de Catalunya, Spain.

Duality of interest The authors declare that there is no duality of interest associated with this manuscript.

\section{References}

1. American Diabetes Association (2010) Diagnosis and classification of diabetes mellitus. Diabetes Care 33(Suppl 1):S62-S69

2. Wells DJ (2004) Gene therapy progress and prospects: electroporation and other physical methods. Gene Ther 11:1363-1369

3. Kay MA, Glorioso JC, Naldini L (2001) Viral vectors for gene therapy: the art of turning infectious agents into vehicles of therapeutics. Nat Med 7:33-40

4. Liu Q, Muruve DA (2003) Molecular basis of the inflammatory response to adenovirus vectors. Gene Ther 10:935-940

5. Buning H, Perabo L, Coutelle O, Quadt-Humme S, Hallek M (2008) Recent developments in adeno-associated virus vector technology. J Gene Med 10:717-733

6. Wang Z, Ma HI, Li J, Sun L, Zhang J, Xiao X (2003) Rapid and highly efficient transduction by double-stranded adenoassociated virus vectors in vitro and in vivo. Gene Ther 10:2105-2111
7. Chen S, Ding JH, Bekeredjian R et al (2006) Efficient gene delivery to pancreatic islets with ultrasonic microbubble destruction technology. Proc Natl Acad Sci U S A 103:8469-8474

8. Ayuso E, Chillon M, Agudo J et al (2004) In vivo gene transfer to pancreatic beta cells by systemic delivery of adenoviral vectors. Hum Gene Ther 15:805-812

9. Ayuso E, Chillon M, Garcia F et al (2006) In vivo gene transfer to healthy and diabetic canine pancreas. Mol Ther 13:747-755

10. Collombat P, Xu X, Ravassard P et al (2009) The ectopic expression of Pax4 in the mouse pancreas converts progenitor cells into alpha and subsequently beta cells. Cell 138:449-462

11. Xu X, D'Hoker J, Stange G et al (2008) Beta cells can be generated from endogenous progenitors in injured adult mouse pancreas. Cell 132:197-207

12. Cheng H, Wolfe SH, Valencia V et al (2007) Efficient and persistent transduction of exocrine and endocrine pancreas by adeno-associated virus type 8. J Biomed Sci 14:585-594

13. Wang AY, Peng PD, Ehrhardt A, Storm TA, Kay MA (2004) Comparison of adenoviral and adeno-associated viral vectors for pancreatic gene delivery in vivo. Hum Gene Ther 15:405-413

14. Inagaki K, Fuess S, Storm TA et al (2006) Robust systemic transduction with AAV9 vectors in mice: efficient global cardiac gene transfer superior to that of AAV8. Mol Ther 14:45-53

15. Nakai H, Fuess S, Storm TA, Muramatsu S, Nara Y, Kay MA (2005) Unrestricted hepatocyte transduction with adenoassociated virus serotype 8 vectors in mice. J Virol 79:214-224

16. Loiler SA, Tang Q, Clarke $T$ et al (2005) Localized gene expression following administration of adeno-associated viral vectors via pancreatic ducts. Mol Ther 12:519-527

17. Maione F, Molla F, Meda C et al (2009) Semaphorin 3A is an endogenous angiogenesis inhibitor that blocks tumor growth and normalizes tumor vasculature in transgenic mouse models. J Clin Invest 119:3356-3372

18. Wang Z, Zhu T, Rehman KK et al (2006) Widespread and stable pancreatic gene transfer by adeno-associated virus vectors via different routes. Diabetes 55:875-884

19. Casellas A, Salavert A, Agudo J et al (2006) Expression of IGF-I in pancreatic islets prevents lymphocytic infiltration and protects mice from type 1 diabetes. Diabetes 55:3246-3255

20. Devedjian JC, George M, Casellas A et al (2000) Transgenic mice overexpressing insulin-like growth factor-II in beta cells develop type 2 diabetes. J Clin Invest 105:731-740

21. Matsushita T, Elliger S, Elliger C et al (1998) Adeno-associated virus vectors can be efficiently produced without helper virus. Gene Ther 5:938-945

22. Ayuso E, Mingozzi F, Montane J et al (2010) High AAV vector purity results in serotype- and tissue-independent enhancement of transduction efficiency. Gene Ther 17:503-510

23. Lock M, McGorray S, Auricchio A et al (2010) Characterization of a recombinant adeno-associated virus type 2 Reference Standard Material. Hum Gene Ther 21:1273-1285

24. Kruse F, Rose SD, Swift GH, Hammer RE, MacDonald RJ (1993) An endocrine-specific element is an integral component of an exocrine-specific pancreatic enhancer. Genes Dev 7:774-786

25. Kruse F, Rose SD, Swift GH, Hammer RE, MacDonald RJ (1995) Cooperation between elements of an organ-specific transcriptional enhancer in animals. Mol Cell Biol 15:4385-4394

26. Garcia-Ocana A, Takane KK, Syed MA, Philbrick WM, Vasavada RC, Stewart AF (2000) Hepatocyte growth factor overexpression in the islet of transgenic mice increases beta cell proliferation, enhances islet mass, and induces mild hypoglycemia. J Biol Chem 275:1226-1232

27. Garcia-Ocana A, Vasavada RC, Cebrian A et al (2001) Transgenic overexpression of hepatocyte growth factor in the beta-cell markedly improves islet function and islet transplant outcomes in mice. Diabetes 50:2752-2762 
28. Fiaschi-Taesch NM, Berman DM, Sicari BM et al (2008) Hepatocyte growth factor enhances engraftment and function of nonhuman primate islets. Diabetes 57:2745-2754

29. Garcia-Ocana A, Takane KK, Reddy VT, Lopez-Talavera JC, Vasavada RC, Stewart AF (2003) Adenovirus-mediated hepatocyte growth factor expression in mouse islets improves pancreatic islet transplant performance and reduces beta cell death. J Biol Chem 278:343-351

30. Lopez-Talavera JC, Garcia-Ocana A, Sipula I, Takane KK, CozarCastellano I, Stewart AF (2004) Hepatocyte growth factor gene therapy for pancreatic islets in diabetes: reducing the minimal islet transplant mass required in a glucocorticoid-free rat model of allogeneic portal vein islet transplantation. Endocrinology 145:467-474

31. Jiang FX, Mehta M, Morahan G (2010) Quantification of insulin gene expression during development of pancreatic islet cells. Pancreas 39:201-208

32. Schwitzgebel VM (2001) Programming of the pancreas. Mol Cell Endocrinol 185:99-108

33. Dai C, Li Y, Yang J, Liu Y (2003) Hepatocyte growth factor preserves beta cell mass and mitigates hyperglycemia in streptozotocin-induced diabetic mice. J Biol Chem 278:2708027087
34. Park MK, Kim DK, Lee HJ (2003) Adenoviral mediated hepatocyte growth factor gene attenuates hyperglycemia and beta cell destruction in overt diabetic mice. Exp Mol Med 35:494-500

35. Mellado-Gil JM, Rosa TC, Demirci C et al. (2011) Disruption of $\mathrm{HGF} / \mathrm{c}-\mathrm{met}$ signaling enhances pancreatic beta cell death and accelerates the onset of diabetes. Diabetes 60:525-536

36. Benkhoucha M, Santiago-Raber ML, Schneiter G et al (2010) Hepatocyte growth factor inhibits CNS autoimmunity by inducing tolerogenic dendritic cells and $\mathrm{CD} 25^{+} \mathrm{Foxp}^{+}$regulatory $\mathrm{T}$ cells. Proc Natl Acad Sci USA 107:6424-6429

37. Futamatsu H, Suzuki J, Mizuno S et al (2005) Hepatocyte growth factor ameliorates the progression of experimental autoimmune myocarditis: a potential role for induction of T helper 2 cytokines. Circ Res 96:823-830

38. Oh K, Iimuro Y, Takeuchi M et al (2005) Ameliorating effect of hepatocyte growth factor on inflammatory bowel disease in a murine model. Am J Physiol Gastrointest Liver Physiol 288: G729-G735

39. Hendrick LM, Harewood GC, Patchett SE, Murray FE (2011) Utilization of resource leveling to optimize ERCP efficiency. Ir J Med Sci 180:143-148. doi:10.1007/s11845-010-0570-7 